\title{
Assessing the performance of international water management at Lake Titicaca
}

\section{Journal Article}

Author(s):

Rieckermann, Jörg (D); Daebel, Helge; Ronteltap, Mariska; Bernauer, Thomas

Publication date:

2006-12

Permanent link:

https://doi.org/10.3929/ethz-b-000020528

Rights / license:

In Copyright - Non-Commercial Use Permitted

Originally published in:

Aquatic Sciences 68(4), https://doi.org/10.1007/s00027-006-0863-0 


\title{
Research Article
}

\section{Assessing the performance of international water management at Lake Titicaca}

\author{
Jörg Rieckermann ${ }^{1}$, Helge Daebel ${ }^{1}$, Mariska Ronteltap ${ }^{1}$ and Thomas Bernauer ${ }^{2, *}$ \\ ${ }^{1}$ Eawag, Swiss Federal Institute of Aquatic Science and Technology, 8600 Dübendorf, Switzerland and Institute of \\ Environmental Engineering, ETH Zurich, 8093 Zurich, Switzerland \\ ${ }^{2}$ ETH Zurich, Center for Comparative and International Studies (CIS) and Institute for Environmental Decisions \\ (IED), 8092 Zurich, Switzerland
}

Received: 9 January 2006; revised manuscript accepted: 30 April 2006

\begin{abstract}
In this article, we study the performance of international water management at Lake Titicaca in order to assess the empirical applicability of a new concept for measuring policy performance. This performance measurement concept $(P E R)$ is a function of three variables: optimum performance $(O P)$, actual performance $(A P)$, and counterfactual performance $(C P)$. In examining the joint management of Lake Titicaca by Bolivia and Peru, we identify practical difficulties in applying $P E R$ and suggest extensions of the concept to assess uncertainty.
\end{abstract}

We find that this measurement concept has several advantages: it takes into account counterfactual performance; the analysis can be performed in a structured, standardized, and transparent manner; and the formal framework allows for an assessment of uncertainty. Problems in applying the concept include: choice of attributes, identification of optimum performance, time-scale, and subjectivity of information. We conclude that, on balance, this approach is superior to other policy performance assessment measures developed to date.

Key words. Performance; international; water; management; Titicaca; uncertainty.

\section{Introduction}

It is virtually a truism that effective international water management is necessary to avoid conflicts over scarce water resources in many parts of the world (Durth, 1996; Marty, 2001; Wolf, 1997; Bernauer, 2002). It is equally obvious, however, that there is no agreement on best management practices, primarily because governance mechanisms and their effects are not yet sufficiently understood. To provide a better scientific basis for designing effective governance mechanisms we need to study a relatively large number of water management cases

* Corresponding author phone: +41-44-632-6466; fax: +41-44-632-1289; e-mail: bernauer@ir.gess.ethz.ch Published Online First: November 22, 2006 worldwide based on a unified analytical framework. Such a unified framework will hopefully allow us to draw valid and reliable inferences from past and ongoing water management efforts, and to identify the key elements of successful (or unsuccessful) water management.

Before we explain why the performance of water management efforts varies across cases and time we need to measure (describe) in an accurate and comparable (across cases and time) manner the performance of water management. To that end we propose to use a policy performance $(P E R)$ metric originally proposed by Underdal (1992), Helm and Sprinz (2000), and Hovi et al. (2003) and recently developed further by Siegfried and Bernauer (2006)

Whether this concept is empirically useful to policy analysts, particularly under conditions of incomplete information, limited resources, vague or ambiguous man- 
agement objectives, and multi-dimensional problem settings, remains open. The international management of Lake Titicaca is, to a large degree, subject to these conditions. Hence it provides an opportunity to assess the challenges in empirically applying the new policy performance measurement concept. In particular, we address the following questions: Is the proposed metric useful to evaluate international water management efforts in a complex setting? What are the conceptual drawbacks? What practical limitations does the analyst face?

The remainder of the article is as follows. We introduce the performance metric PER and propose a simple method that assigns degrees of uncertainty to each attribute as a function of information sources and verifiability of reported information (section "Measuring performance"). We present some background information on the Titicaca catchment and the problems faced by its riparians (section "Empirical application: Lake Titicaca basin"). We outline the problem solving efforts by Peru and Bolivia (section "Problem solving efforts") and assess the performance of these efforts (section "Performance of the problem solving efforts"). We discuss the advantages and challenges in using the PER metric and conclude. Why international water management at Lake Titicaca has thus far had only modest to little success, will be alluded to only in passing, for the objective of this article is to measure performance, and not to explain it.

\section{Measuring performance}

\section{Performance metric}

The performance score $P E R$, originally proposed by Underdal (1992), Helm and Sprinz (2000), and Hovi et al. (2003) and recently developed further by Siegfried and Bernauer (2006), is

$P E R=\frac{A P-C P}{O P-C P}$

where $A P$ is the actual performance (expressing the actual state of an aquatic system with regard to a specific attribute, e.g., water pollution), $O P$ is the optimal performance (expressing an ideal state or final goal of the management effort), and $C P$ is the counterfactual performance (expressing outcomes that would have occurred without the management action to be assessed).

The conceptual and arguably also the empirical benefits of this approach in comparison with other ways of assessing policy performance are:

- Counterfactual performance is taken into account. By considering $C P$ in the assessment, PER captures the causal element associated with effective management, i.e., PER measures the extent to which observed changes in the targets of management efforts (e.g. water quality) can be traced back to the management effort, rather than to other causes. This causal element is missing in most other approaches to measuring policy performance, which tend to focus on some forms of $O P$ and $A P$ alone.

- The concept imposes a transparent assessment of policy performance. Hence it ascertains exposure of policy analysts to scientific debate of assumptions and information that flow into the calculation of PER scores.

- The concept is flexible and can thus be easily extended. E.g., the analysis can start by assessing PER with respect to one or very few attributes (see below) and expand to additional attributes as complementary or contradictory information is acquired.

- PER can be computed based on absolute values (e.g., annual water discharges) as well as relative values (e. g., extent of achievement of specific policy goals expressed in percentages).

- It sets a lower and an upper bound and (with some exceptions) standardizes $P E R$ values between 0 and 1 (Siegfried and Bernauer, 2006; Helm and Sprinz, 2000). This allows for comparison of different water management efforts.

In the case of Lake Titicaca, we chose to perform the analysis on a relative basis instead of absolute numbers. The reason is that the assessment necessitates integration of qualitative and quantitative information from different sources even at the level of single attributes (see section "Performance of the problem solving efforts"). Values between 0 (= entirely ineffective management $)$ and 10 (= perfect management) are assigned to the three model parameters $A P, C P$ and $O P$ for each management attribute. By definition, the ordinal scale is linear, the desired outcome $O P$ is set to $10, A P$ and $C P$ are established based on the available information. It is important to note that $C P$ as well as $O P$ cannot be observed directly and empirically. They have to be deduced from secondary information. $C P$ can, for example, be established through gametheoretic models, expert interviews, or with reference to the status quo ante (see also Siegfried and Bernauer, 2006). For this study, we relied on expert assessments and the status quo ante (see below).

\section{Uncertainty analysis}

Besides the benefits listed above yet another potential advantage of the approach evaluated here is that it permits a quantitative uncertainty analysis. This is important in our study, because we deliberately picked an empirical case where information is rather hard to obtain and potentially of limited reliability. In this section we propose a method for assessing the uncertainty of PER scores before we move to the empirical application.

The uncertainty analysis of the calculated results, as proposed below, comprises two elements: first, assess- 
ment of the uncertainty of the parameters $A P, C P$ and $O P$; second, assessment of the uncertainty of the PER metric by means of propagating the parameter uncertainties through equation 1 . Whereas the propagation of uncertainty is a rather technical issue and often straightforward, the elicitation of the uncertainties of $A P, C P$ and $O P$ is quite intricate.

Assessing the uncertainty of $A P$ and $C P$. In many if not most cases of international water management, the assessment of uncertainty of the individual parameters of PER critically depends on the type and nature of the processed information. Leaving aside cases where an uncertainty estimate is already provided with the available data, we distinguish two situations.

In the first situation, the analyst has access to enough numerical information to use standard quantitative statistical techniques to obtain estimates of uncertainty (e.g., standard deviations). This mainly concerns the identification of actual performance $A P$, but might also be relevant for $C P$ (e.g., when a simulation model is used).

In the second situation, the analyst is dependent on data that does not readily allow for the assignment of measures of uncertainty. This problem is likely to occur in many empirical cases, for example, because: (i) some of the available data is too sparse to apply quantitative techniques; (ii) resources available to the analyst preclude rigorous quantification of uncertainty; (iii) a management effort's anticipated long-term effects are difficult or impossible to quantify (e.g. impact of environmental education).

We submit that uncertainty analysis is a complex but necessary task, notably because the second situation will be quite frequent in PER assessments. Specifically, we propose an additive model to relate uncertainty of $A P$ or $C P$ to the reliability of the underlying information (e.g., estimated reliability of the source, credibility of experts, availability of up-to-date information, verifiability of data, etc. $)^{1}$ :

$\sigma_{\theta i}=\sum_{k} w_{k} \cdot \sigma_{\theta k}$

where $\sigma_{\theta i}$ is the uncertainty of a parameter of the metric (e.g., $A P$ ), reported as the estimated single standard deviation, $w_{k}$ is a specific weight of an attribute (e.g., source of information) and $\sigma_{\theta k}$ is the expected uncertainty associated with the credibility of the attribute (e.g. information from a peer-reviewed scientific paper is likely to be more reliable than information from an internet resource or a

\footnotetext{
1 One could also assess the uncertainty of $O P$. We do not include such an assessment in this article because $O P$ is likely to change only over longer periods of time (e.g. due to new scientific research results, changing social value systems). Moreover, our empirical application focuses on a case where policy-goals (and thus $O P$ ) are relatively clear and have not changed substantially over the time-period we focus on.
}

qualified guess). The use of standard deviations as uncertainty measures does not correspond rigorously to their statistical meaning. In most cases neither the underlying statistic is known nor can it be estimated empirically. We assume that a standard deviation describes the width of a (yet unkown) distribution, avoiding representation of the entire range of uncertainty (e.g. a $99 \%$ confidence region). If, in contrast, we used a $\Delta_{\theta k}$ or $\Delta_{\theta i}$ respectively, coverage of the entire range of uncertainty or even a uniform distribution might erroneously be assumed.

To illustrate the procedure, we use a brief hypothetical example. The analyst tries to assess the uncertainty of actual performance $A P$ (possible range 0 to 10 ) for two attributes. Let us assume that both attributes A and B are related to the goal of reducing water pollution: (A) construction of relevant infrastructure and (B) source control measures. The information found for (A) is that the construction of a wastewater treatment plant is reported, on the internet page of a water management authority, to be nearly completed. For (B) the information is that a scientific paper reported an environmental education program that is implemented to $50 \%$. In assessing the value of the information, the analyst notes that (i) the source of information (SI) and (ii) the reported type of measure (ME) contribute to overall uncertainty about the $A P$ score. According to the analyst's judgment about which factor is more decisive he/she assigns weights that sum up to 1 (e.g., $\left.\mathrm{w}_{\mathrm{SI}}=0.6, \mathrm{w}_{\mathrm{ME}}=0.4\right)$. She assumes that the peerreviewed scientific paper is fairly reliable, whereas information on the internet page of a water management authority might be deliberately biased. She assigns standard deviations (in units of $A P)$ accordingly $\left(\sigma_{\text {SI,paper }}=1.0\right.$, $\sigma_{S I, w e b}=3.0$ ). With regard to the reported type of policy measure, she considers constructed engineering works to be easily verifiable and thus quite certain $\left(\sigma_{M E \text {,eng.work }}=\right.$ 0.5 ). The judgment about a "soft" measure implemented half-way, such as an environmental education program, could be a very subjective estimate and is therefore considered rather uncertain information $\left(\sigma_{M E \text {,edu.prog. }}=2.0\right)$. Applying eq. (2), the uncertainty for $A P$ in respect to each attribute is calculated as $\sigma_{A P, A}=0.6 \cdot 3.0+0.4 \cdot 0.5=$ 2.0 and $\sigma_{A P, B}=0.6 \cdot 1.0+0.4 \cdot 2.0=1.4$. The conclusion is that, based on available information and the analyst's judgment about its reliability, $A P$ for attribute $\mathrm{B}$ is slightly more trustworthy than for attribute A.

The advantages of this approach are that: (i) it makes the use of subjective information explicit; (ii) it ensures sufficient transparency to allow for a critical review; (iii) it is at least consistent in a relative sense, as it leads to similar uncertainties for all attributes which use similar information. At this point, we emphasize that we are very conscious of the fact that the "objective" uncertainty in regard to data for a given attribute, if it exists, might not be well captured with this approach. Nonetheless, we agree with Morgan and Henrion (1990) that "elicited ex- 
pert judgments may be seriously flawed but are often the only game in town". Adopting a Bayesian viewpoint, uncertainty about data for any of our three model parameters is necessarily based on the actual state of knowledge of the analyst. In this respect the proposed procedure is consistent because estimated uncertainties derive from the analyst's opinion about plausible values for all relevant variables.

Propagation of uncertainties. Once the parameter uncertainties are assessed we can move to analyzing how these uncertainties affect the computed results. From the many methods available for studying the propagation of uncertainties we apply a linear method, widely known as Gaussian error propagation (see also Fig. 1):

$\sigma_{P E R}=\sqrt{\sum_{i}\left(\frac{\partial P E R}{\partial \theta_{i}} \cdot \sigma_{\theta i}\right)^{2}}$

where $\sigma_{P E R}$ is the uncertainty in performance (PER), $\partial P E R / \partial \theta_{i}$ is the linearization of the PER metric at the individual parameter value $\theta_{i}$ (e.g., $A P$ ), and $\sigma_{\theta i}$ is the expected uncertainty of the individual parameter.

This technique is useful for our purpose because: (i) it provides an explicit consideration of uncertainties, where each parameter's contribution is not only clearly visible but also divided into the contribution of sensitivity and uncertainty (Fig. 1); (ii) it is simple and therefore widely known in the natural sciences; (iii) it helps to develop an intuition about how uncertainties combine and propagate; (iv) it contributes to an efficient allocation of research resources in order to get more reliable results (primarily through an assessment of which additional information would be most valuable).

The relative contribution of a single parameter to the overall uncertainty of PER $\left(\delta_{P E R, \theta i}^{e r r}\right)$ can be computed from

$\delta_{P E R, \theta i}^{e r r}=\left(\frac{\partial P E R}{\partial \theta_{i}} \cdot \sigma_{\theta i}\right)^{2} \cdot \frac{1}{\sigma_{P E R}^{2}}$

Note that there are two major assumptions inherent in this approach (eq. 3 and 4): (1) it requires independence between the parameters $A P, C P$ and $O P$, and (2) it assumes that linearization within parameter ranges $(=$ best estimate + uncertainty, see Fig. 1) is a valid simplification.

(1) From a mathematical point of view, it would be easy to extend eq. 3 and 4 to account for (linear) dependence between the parameters. Moreover, one could argue that in many cases especially $A P$ and $C P$ will be correlated somehow because similar sources of information are consulted for their estimation. Yet, it would be nearly impossible to assign degrees of dependence on a formal basis. The results would, therefore, not be more reliable than the results from the proposed simplified approach.

(2) Because uncertainties in policy analysis are expect-

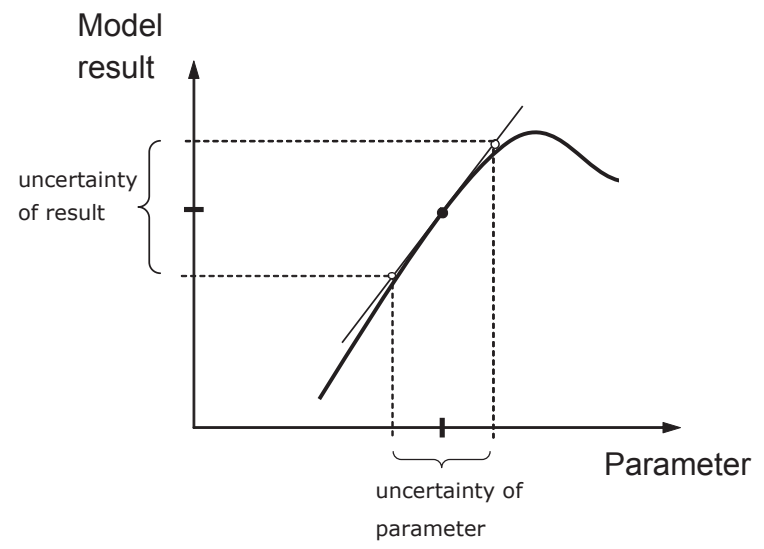

Figure 1. Conceptual sketch of the linear error propagation for a model with a single parameter. The final uncertainty in the model result (thick line) is determined by two elements: (i) the sensitivity of the model result to the parameter of concern at its estimated value (slope of linear approximation, thin line); (ii) the uncertainty range of the parameter (dotted lines).

ed to be rather large compared to the nonlinearities in the model, it is important to ascertain that the assumption of linearity is valid. If this assumption is violated the linear error propagation leads to incorrect results. We analyzed the impact of non-linearity of $P E R$ only with regard to expected uncertainties in $C P\left(\sigma_{C P}<2\right)$, because: (i) it is clearly visible from eq. 1 that the $P E R$ metric is linear with regard to $A P$; and (ii) $O P$ is our reference for optimal performance and is thus certain by definition (because we use relative assessment on a $0-10$ scale we set $O P=10$ ). We found that the linear approximation leads to reliable results when $C P$ is smaller than $5=O P / 2$ (results not shown). This holds to a large degree in our empirical case (see section "Performance of the problem solving efforts"). In more problematic cases, Monte Carlo techniques could be applied. They would demand implementation of the PER metric into a computer simulation model (see e.g. Liu, 2001; Saltelli, 2000; 2004).

\section{Empirical application: Lake Titicaca basin}

\section{Background information}

Lake Titicaca lies in the South American Andes at the border of Bolivia and Peru at an average altitude of $3,810 \mathrm{~m}$ above sea level. It is known as the highest of the world's great lakes. It covers $8,400 \mathrm{~km}^{2}$, has a volume of $932 \mathrm{~km}^{3}$, and constitutes the freshwater source for nearly three million people (Revollo et al., 2003). Lake Titicaca is located in the upstream part of a large watershed (Fig. 2) that also includes the river Desaguadero, Lake Poopó, and the salt lake Salar de Coipasa. It is therefore referred to as the TDPS system. The TDPS watershed covers an area of $143,900 \mathrm{~km}^{2}$. 

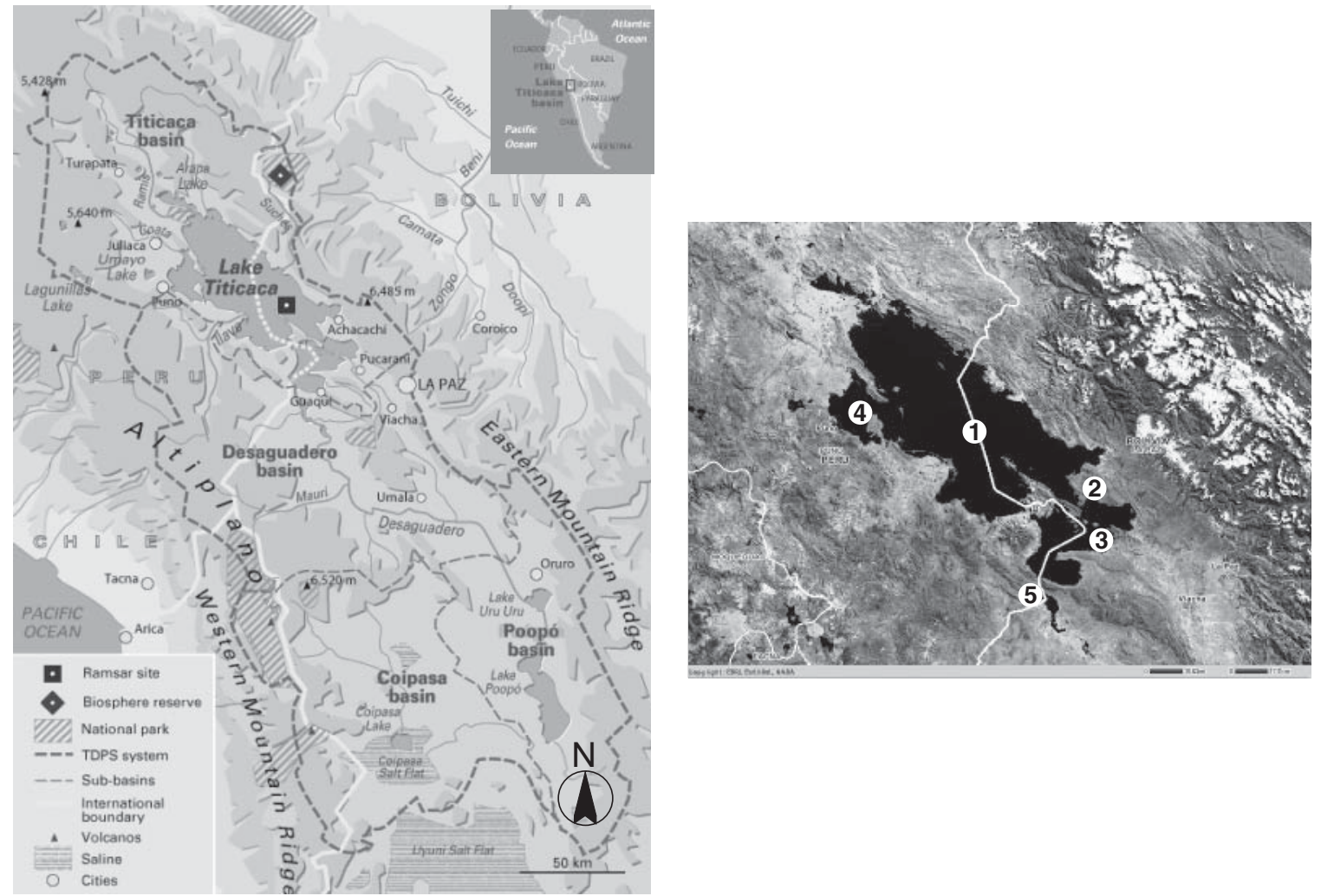

Figure 2. Left: Geographical overview of the TDPS basin: Lake Titicaca, Río Desaguadero, Lake Poopó, and Coipasa Salt Marshes. (UNESCO, 2004b) Right: Satellite image of the Lake Titicaca basin and its water bodies (modified from NASA (2004): (1) Lago Mayor, (2) Tiquina Strait, (3) Lago Menor, (4) Bahía de Puno, (5) Outflow to Desaguadero River).

Precipitation in the TDPS system occurs mainly from December to March and amounts to about $700 \mathrm{~mm}$ per year around Lake Titicaca. It is most abundant directly above the lake and constitutes the largest water input into the lake $(55 \%)$. The residual water input stems from rivers and varies considerably over the year. It is practically zero during the dry season and up to 10 times the average discharge in the rainy season. Diffuse groundwater leakage into the lake from coastal aquifers is believed to be negligible (Dejoux and Iltis, 1992).

Water is removed from Lake Titicaca mainly by evaporation (95\%). The remaining share is drained by the Río Desaguadero, which has a discharge of around $20 \mathrm{~m}^{3} \mathrm{~s}^{-1}$ at the outflow and $30 \mathrm{~m}^{3} \mathrm{~s}^{-1}$ after contributions from some tributaries. It connects Lake Titicaca with Lake Poopó, which is located $400 \mathrm{~km}$ downstream to the South (Fig. 2). Despite of its small flow, the Desaguadero river is the most important water resource for the arid Bolivian highlands (Paredes and Gonfiantini, 1999).

The most important element of the TDPS system is Lake Titicaca, mainly because of its size and upstream location. It consists of three main water bodies (Fig. 2) of which the largest and deepest is the Lago Mayor (1). The latter lies mainly in Peruvian territory. The Tiquina Strait (2) connects the Lago Mayor to the Lago Menor
(3). The latter is the second biggest region of the lake. Its largest part is located in Bolivia. The third lake region is the Bahia de Puno (4), a large and shallow bay in front of Puno, which is the main settlement on the western coast of Lago Mayor. As indicated above, the river Desaguadero (5), which is the only outflow of the lake, is located at its southern end.

Isotopic mixing studies have established that the water flow is unidirectional from Lago Mayor to Lago Menor. The latter is relatively shallow and has a rather short residence time. The water from the outer bay of Puno is reported to be well mixed with the water in Lago Mayor, but the inner Puno bay seems rather closed (Paredes and Gonfiantini, 1999), which leads to severe pollution problems (see section "Performance of the problem solving efforts - Water quality management").

The natural resources of the TDPS system have been under strong anthropogenic pressure for the past few decades. This pressure has been exacerbated by serious socio-economic problems in Bolivia and Peru. Poverty is widespread in the entire TDPS basin. It is affecting both rural and urban populations (ALT, 2003). Infant mortality is high. Only around $20 \%$ of the population has direct access to drinking water and sanitation. Agriculture is the main source of income in the TDPS system. It is mainly 
carried out on small and dispersed lots. Modern, efficient irrigation and land cultivation equipment is very rare. Inefficient equipment and the introduction of rapidly reproducing cattle and sheep have resulted in overexploitation of land. This, in turn, has led to soil erosion and poor natural water regulation capacity (Revollo et al., 2003). Mining, another important economic activity in the TDPS area, has also contributed to environmental degradation. Table 1 provides a basic summary of socio-economic data on the TDPS basin.

\section{Problems}

As regards water-related issues, there are three major problems in the TDPS system: (i) extreme hydrological events; (ii) unsustainable water use; (iii) local water pollution.

Extreme hydrological events (floods and droughts). Climatic conditions in the Altiplano are characterized by high variability and recurrent extreme events (Bourges et al., 1992). These conditions cause sequences of very dry and very wet years, which lead to economic losses due to floods and droughts that affect Peru and Bolivia alike. In 1983 (drought) and 1986 (flood), for example, damages were reportedly more than 120 million USD (Revollo et al., 2003).

Unsustainable water use. Although Lake Titicaca has a very large volume, long-term water demand in the region exceeds the natural supply. As indicated above, evaporation amounts to $95 \%$ of the lake's input. Moreover, the mean annual surplus in the water budget is estimated to be only $21 \mathrm{~m}^{3} \mathrm{~s}^{-1}$ (this is not the outflow of the Desaguadero, but rather the balanced surplus, also considering the threat of chronic salination). This means that Peru and Bolivia must coordinate and prioritize particular forms of water use (e.g., for irrigation and industrial purposes) in order to avoid a dramatic lake level decrease. For Bolivia in particular the stakes are high because it is virtually forced to ascertain a minimum flow in the Desaguadero so as to avoid salination problems in the downstream regions of the TDPS.

Local water pollution. Because of the lake's large water body and the hydraulic retention time of more than 1,000 years pollution problems are (to date) local rather than international. However, declining water quality is perceived in both riparian countries as a severe local problem at certain "hot spots". Several studies have reported water contamination problems in the inner bay of Puno (Dejoux and Iltis, 1992; Méndez Quincho, 2001; Northcote et al., 1989; Revollo et al., 2003; Costantini et al., 2004). This part of Lake Titicaca is located in Peru. Serious water pollution has also been reported for Copacabana Bay, Bolivia (La Prensa, 2003). As regards future con-
Table 1. Basic socio-economic data on the Peruvian and Bolivian part of the TDPS system (ALT, 2003).

\begin{tabular}{lll}
\hline & $\begin{array}{l}\text { Peruvian part } \\
\text { of TDPS }\end{array}$ & $\begin{array}{l}\text { Bolivian part } \\
\text { of TDPS }\end{array}$ \\
\hline Population (pop) & $1,080,000$ & $1,159,000$ \\
$\%$ of total & 48.2 & 51.8 \\
Average pop density $\left(\mathrm{pop} / \mathrm{km}^{2}\right)$ & 17.6 & 15.6 \\
Maximum density (pop $\left./ \mathrm{km}^{2}\right)$ & 215 & 245 \\
Minimum density $\left(\mathrm{pop} / \mathrm{km}^{2}\right)$ & 2.0 & 2.3 \\
Rural pop (\%) & 60.8 & 47.9 \\
Urban pop (\%) & 39.2 & 52.1 \\
Annual growth rate $(\%)$ & 1.6 & -1.6 to 9.2 \\
Pop trends & Rural and urban & Rural pop \\
& pop decreasing & decreasing \\
Pop in poverty situation $(\%)$ & 73.5 & 69.8 \\
Connection to drinking water & 19 & 24 \\
$\quad$ system (\%) & & 13 \\
Sewage system coverage $(\%)$ & 20 &
\end{tabular}

tamination problems, Bolivia and Peru are equally concerned that population growth might increase stress on their water resources.

\section{Problem solving efforts}

Cooperative efforts between the governments of Peru and Bolivia aimed at managing the TDPS system extend back to 1906 (Sanjinés-Goytia, 2001). Yet, the first formal agreement on studying and managing Lake Titicaca's water resources was signed in Lima in 1955. This agreement declared 'the indivisible and exclusive joint ownership of both countries of the waters of the lake.' In 1986 this cooperative framework was put on a more institutionalized footing through a bilateral sub-commission, SUBCOMILAGO. This commission asked for assistance from the European Community (now the European Union) to create a general framework for joint watershed management (Querol, 2003).

Between 1991 and 1993 European consulting and engineering companies carried out a range of studies on Lake Titicaca and the TDPS system. These studies led to a 'Binational General Master Plan for the Development of the Integrated Region of Lake Titicaca'. This plan, with a time-frame of 20 years, constitutes the basic reference for managing the watershed.

In 1996, the two riparian countries established the Binational Autonomous Authority for Lake Titicaca (ALT). The ALT includes representatives from both countries. Its main responsibility is to ensure the implementation of the master plan. To that end it received a high degree of autonomy in technical and administrative matters. The Special Project Lake Titicaca (PELT) in 
Peru and the Bolivian Operational Unit (UOB) in Bolivia are the national operational units under the umbrella of the ALT.

In the following section we will study the performance of the ALT (from its creation in 1996 until September 2004) and its master plan. This assessment is carried out in respect to three main objectives of the joint watershed management effort. These objectives are closely related to the three major problems listed in section "Empirical application: Lake Titicaca basin - Problems".

\section{Performance of the problem solving efforts}

In this section we assess the performance of the binational authority (ALT) and its master plan in tackling the three major water-related problems of Lake Titicaca listed in section "Empirical application: Lake Titicaca basin". In carrying out the assessment we apply two restrictions to simplify the analysis, particularly in view of limited data. First, we focus on the upstream part of the TDPS system, i.e., the Lake Titicaca catchment. Second, we examine performance in 2004, i.e., eight years after the master plan was initiated - including time-dynamics in computing PER (see Siegfried and Bernauer, 2006) would require much more detailed data than is currently available on Lake Titicaca. Moreover, the performance assessment is carried out on the basis of existing information since our goal is to evaluate the usefulness of a new performance measurement concept, rather than to generate new data on Lake Titicaca and its management. It is obvious that input of new, original data into our assessment framework, as outlined below, could improve the reliability of calculated performance scores or even change some of their values.

The performance measure PER is calculated for three management objectives (see section "Empirical application: Lake Titicaca basin"): (i) flood and drought protection; (ii) water use management; (iii) water quality management. For each objective the calculation is based on a set of operational attributes, e.g., existence of regulation works, source control measures. To that end, $O P, A P$ and $C P$ are established with reference to a set of operational management tasks related to the three main objectives.
As indicated in the methods section "Measuring performance", optimal performance is always set to 10 . Note that defining the operational management goals of the master plan as $O P$ is a simplification that may, in some cases, be problematic from an ecological or economic standpoint. For example, ecologically optimal solutions may not be Pareto-improving from an economic standpoint, and vice versa. As regards the assessment of $C P$, we used best estimates from expert interviews, official documents, and secondary literature. Because $C P$ cannot be observed directly and empirically and thus poses problems of reliability and accuracy, we assess the uncertainty of each value.

For the assessment and propagation of uncertainty we follow the procedures outlined in section "Measuring performance". The assessment of parameter uncertainty of $A P$ and $C P$ is based on two terms: (i) reliability of the source of information and (ii) verifiability of the implemented problem solving measure (see Table $2 \mathrm{a}$ for details and numeric values). From this information, the individual uncertainties for all attributes were computed with eq. 2 , using equal weights $w_{i}$ for each quantity (Table $2 \mathrm{~b}$ ). The results of the performance assessment are summarized in Table 3, together with local sensitivity measures and relative error contributions from eq. 3 and 4. Uncertainty is expressed as the expected single standard deviation and is annotated in brackets (e.g., $A P=5(\sigma=1)$ ).

\section{Flood and drought protection}

Due to very high seasonal and annual variability of precipitation - the latter occurs mainly on the lake surface - severe floods and droughts occur in the lake area approximately every 10 years (Bourges et al., 1992). The master plan proposed measures at three different levels to attenuate the weather effects on the lake's water level fluctuations: (i) controlling the inflow into the lake by damming four tributary rivers; (ii) controlling the outflow by installing floodgates to retain the water; (iii) dredging initial parts of the Desaguadero River to provide a higher hydraulic capacity to manage the risk of flooding (ALT, 2004). Our assessment of performance regarding flood and drought protection concentrates on two attributes: (i) implementation of regulation works; (ii) level of natural retention by means of source control.

Table 2a. Assigned degree of uncertainty (in units of AP or CP) as a function of (a) source of information and (b) verifiability of reported measure.

\begin{tabular}{|c|c|c|c|c|c|c|c|c|}
\hline \multirow{2}{*}{$\begin{array}{l}\text { Uncertainty term } \\
\text { Category }\end{array}$} & \multicolumn{5}{|c|}{ Source of information } & \multicolumn{3}{|c|}{ Verifiability of measure } \\
\hline & $\begin{array}{l}\text { Scientific } \\
\text { paper }\end{array}$ & Report & $\begin{array}{c}\text { Expert } \\
\text { interview }\end{array}$ & $\begin{array}{l}\text { Press } \\
\text { article }\end{array}$ & $\begin{array}{l}\text { Qualified } \\
\text { guess }\end{array}$ & Structure & Monitoring & $\begin{array}{c}\text { Soft } \\
\text { Measures }\end{array}$ \\
\hline Std. Dev. & 0.1 & 0.25 & 0.5 & 1.0 & 2.0 & 0.0 & 0.5 & 1.5 \\
\hline
\end{tabular}




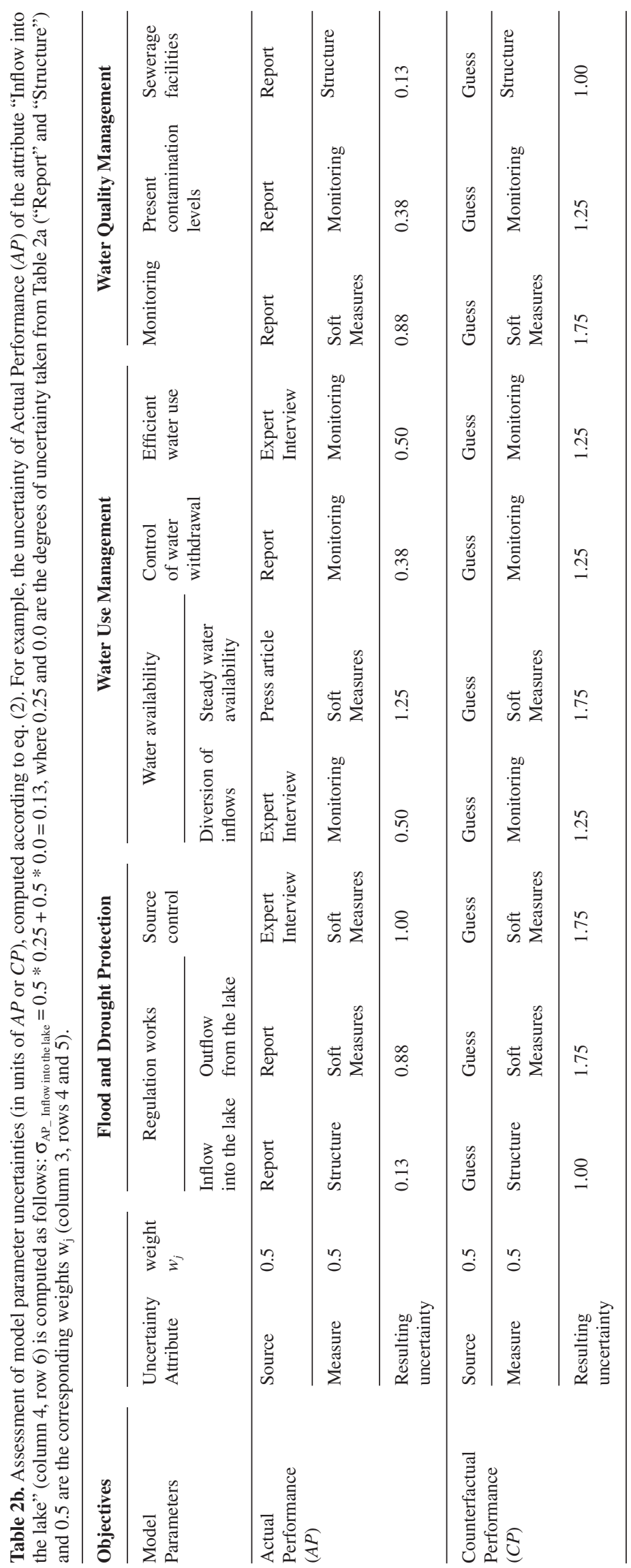




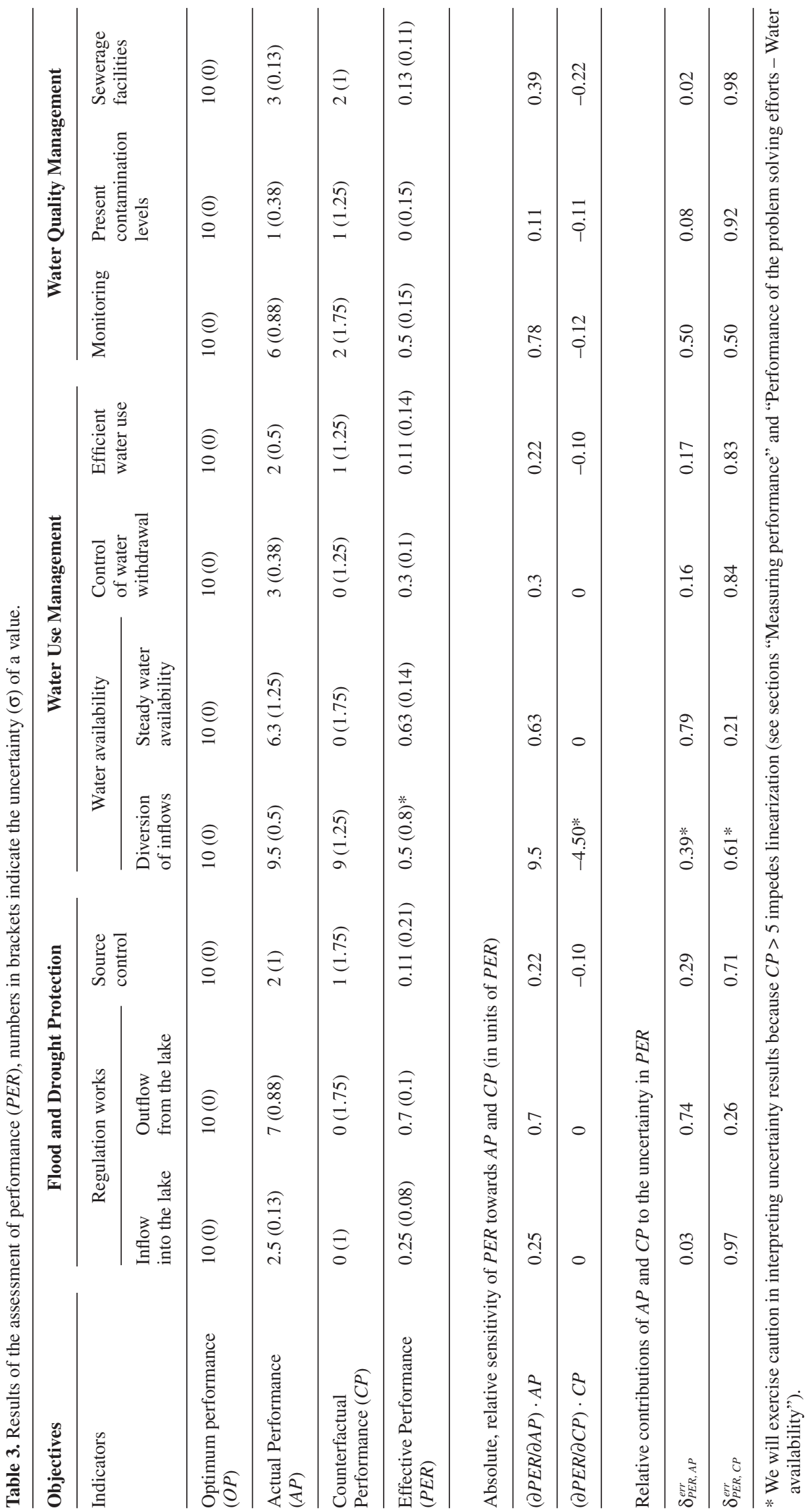


Regulation works. A primary attribute for assessing implemented flood and drought protection measures is the observed variation of the lake level. According to the master plan (ALT, 2003) the water table should be kept between 3,808 and 3,811 m.a.s.l. Data received from PELT show that this goal has been met during the last eight years, even in 2001 - a year with high potential flooding risk. From a statistical point of view, though, a period of eight years is far too short to provide meaningful answers in view of a 10-year hydrological cycle. We therefore argue that the installation of regulation measures represents a more reliable indicator for the current state of flood and drought protection, as long-term hydrological modeling was the basis of their design.

Inflow regulation: (Revollar, 2004b) reports that one of the four planned civil works for lake inflow regulation has been realized $(A P=10 \cdot 1 / 4=2.5(\sigma=0.13))$. The standard deviation of 0.13 is computed from equation 2 as follows: First we classify the information about "inflow regulation" measures with respect to the source of information and its verifiability. A report is associated with an uncertainty of 0.25 . Because inflow regulation measures are, in this case, engineering works (i.e., "structures"), they are highly verifiable and thus associated with an uncertainty of 0.0 (see Table 2a). Second, we assign proper scaling constants $\mathrm{w}_{\mathrm{j}}$. As we have no reason to prefer either the source of information or the verifiability, we assign equal weights of 0.5 to each. From equation 2 we obtain $\sigma_{\text {Inflow into the lake }}=0.5 \cdot 0.25+0.5 \cdot 0.0=0.13$ (Table $2 b$, column 4 , row 6 ). For the sake of brevity, we omit the detailed information in the following sub-sections and just report the value of the uncertainty $(\sigma)$ for each parameter. Assuming that without the ALT's efforts this would not have been done because of missing incentives and financial support $(C P=0(\sigma=1)), P E R$ is 0.25 $(\sigma=0.08)$ for inflow regulation (compare Table 3$)$.

Outflow regulation: It is reported that the installation of the floodgates was completed in $2001(100 \%)$ and $40 \%$ of the necessary dredging has been carried out (Revollo et al., 2003), which results in $A P=7(\sigma=0.88)$. Most probably this would not have materialized without the ALT due to lack of funding and regional incentives $(C P=0(\sigma=1.75))$, which results in a performance score for outflow regulation of $0.7(\sigma=0.1)$.

Averaging the two results, we conclude that the ALT is approximately $50 \%$ effective in flood and drought protection, with reference to the goals set by the master plan. The rather small degree of uncertainty mainly stems from the fact that the available information is easy to crosscheck (source: reports, measures: engineering structures, see Table 2b).

Source control of floods and droughts. Droughts and floods are not only linked to extreme weather conditions. Another important factor is the natural regulation capac- ity of the basin. This regulation capacity is rather weak in the Titicaca catchment because of poor land management (Revollo, 2001). Due to overexploitation the basin has a lower capacity to retain water during wet weather and to ensure water availability during dry weather. Civil works as mentioned above represent only a re(!)-action to poor water retention. More sustainable measures, such as programs promoting and/or realizing source control actions (e.g., reforestation), are another indicator for flood and drought protection. From interviews with experts and decision-makers in the region we learned that such programs are promoted by ALT, but not to a large extent. It seems likely that activities of other governmental or international institutions as well as NGO's in this area are more substantial than those of ALT. Hence, we estimate a PER of only $11 \%(21 \%)(A P=2(\sigma=1), C P=1(\sigma=$ $1.75)$ ). Note that uncertainty of the computed score is rather high compared with the best estimate. The relative error contributions $\delta_{P E R, \theta}^{e r r}$ indicate that the major fraction of uncertainty stems from counterfactual performance. The larger standard deviation in this case results mainly from the difficulty of verifying "soft" measures (compare Tables $2 \mathrm{~b}$ and 3 ).

\section{Water use management}

Although Lake Titicaca constitutes a very substantial freshwater source, the amount of water that can be extracted for usage in agriculture, industry and private households is limited due to very high evaporation. In addition, future water demand is predicted to be four to five times higher than the usable water quantities (Revollo, 2001). Proper water use management is therefore essential.

Water availability. It is important that water inflows are not diverted from the basin and that sufficient water is available at all times.

Diversion of inflows: According to Crespo (2004) about $95 \%$ of the flow in the tributary rivers currently reaches the lake $(A P=9.5(\sigma=0.5))$. This outcome is mainly the result of the longstanding joint management effort of Peru and Bolivia, and not specifically a success of the ALT in recent years $(C P=9(\sigma=1.25))$. The ALT's performance in preventing diversion projects is therefore $50 \%(\sigma=80 \%)$. As to uncertainty, $C P$ is rather large. As indicated in section "Measuring performance", the assumption of linearity could be violated for scores higher than 5 . The uncertainty estimate should thus be regarded with caution.

Steady water availability: Permanent access to water depends on existing natural or artificial retention capacity. It is therefore closely linked to the mentioned regulation works for flood and drought protection. Appropriate measures are controlling in- and outflows. Dredging of the Desaguadero is purely a flood control measure and is 
therefore considered independent from the water availability assessment. The performance score is roughly $60 \%$ $(\sigma=14 \%)(A P=6.3(\sigma=1.25), C P=0(\sigma=1.75))$.

Control of water withdrawal. Besides ensuring availability (a supply side measure), control of water withdrawal (a demand side measure) is also crucial. According to its general objective, the ALT should "dictate norms of management control [...] of the water resources" (UNESCO, 2004a). Because control is only possible on the basis of good knowledge about the current situation, a detailed and accurate overview over all main withdrawals from the watershed is needed. Ideally, legal norms for water use should also be implemented $(=O P)$. We have not found any information on such monitoring, nor any evidence for control systems or legal norms at the binational, national, or local level (Crespo, 2004). However, the ALT reports to have a geographic information system in operation (ALT, 2004). This suggests that the basis for monitoring and regulating water withdrawals exists. Additionally, the work of ALT seems to have helped in increasing environmental awareness, particularly at the level of local communities. According to our information the ALT is in the process of establishing a control strategy for water demand in agreement with local institutions $(A P=3(\sigma=0.38))$. Without the ALT these efforts would probably not have been made $(C P=0(\sigma=1.25))$. Performance is thus in the order of $30 \%(\sigma=10 \%)$ for control of water withdrawal.

Efficient water use. Since about $90 \%$ of the water withdrawal is used for irrigation (Revollo, 2001), the effectiveness of irrigation techniques is very important for sustainable water use. ALT (2004) states that "[...] a number of actions are considered to optimize the water use in other projects in actual operation as well as in traditional irrigation areas". Some programs for promoting water-saving techniques such as drop irrigation or for reintroducing efficient ancient raised bed cultivation exist. However, similarly to reforestation efforts, these programs are rather sparse and weak $(A P=2(\sigma=0.5))$. According to Crespo (2004), the ALT support is helpful in these programs but they are also promoted mainly by other actors $(C P=1(\sigma=1.25))$. The performance score for promotion of more efficient techniques is in the order of $11 \%(\sigma=14 \%)$.

\section{Water quality management}

Although Borre et al. (2001) mention accelerated eutrophication as an upcoming challenge, Revollar (2004a) reports that there are no widespread problems with water quality yet. Pollution mostly stems from untreated sewage discharges (Table 1) and occurs mainly close to densely populated areas: Puno Bay (most severely affected), the Coata River at Juliaca and the Seco River draining parts of El Alto (La Paz). Press articles also mention water pollution at Copacabana and Cohana Bay (La Prensa, 2003). Northcote (1992) points out that it is difficult to assess the problem because the places mentioned above are the only ones for which some information is available, but other areas might also be affected. Because no detailed objectives of the ALT for water quality exist, we apply the following indicators to judge the ALT's performance in respect to water quality: (i) monitoring efforts; (ii) present contamination levels; (iii) the existence of sewerage treatment facilities.

Monitoring. To our knowledge, the only area monitored on a monthly basis is the Inner Puno Bay, where eutrophication and pathogens are a major problem (Northcote et al., 1989; Costantini et al., 2004). This problem is caused by a high amount of anthropogenic discharges - only about $30 \%$ of Puno's sewage is treated in stabilization ponds, the major part is discharged into the bay (Méndez Quincho, 2001). The weak mixing between bay water and the lake's main water body aggravates the problem (Paredes and Gonfiantini, 1999).

Oxygen, nitrogen and phosphorus concentrations are regularly measured at different locations and depths of the Bay (Méndez Quincho, 2001; Revollar, 2004a). Yet, the operators of the sewage treatment ponds do not have much knowledge about their current loads and emissions (Revollar, 2004b). In Copacabana, water quality measurements were carried out in 1999. But no study about environmental impacts on the lake was performed, as should be done by the regional authorities and municipalities (La Prensa, 2003).

We acknowledge, however, that the ALT is active in: (i) establishing a contamination model of the lake; (ii) monitoring different spots in the lake on a trisemesteral basis; (iii) providing the analytical facilities for water quality studies (Revollo et al., 2003). Furthermore, Revollar (2004b) notes that the ALT triggered an initiative to form a committee to coordinate and supervise monitoring programs.

Based on the aforementioned information, around $60 \%$ of monitoring programs appear to have been installed $(A P=6(\sigma=0.88))$. Without the ALT this would probably not have be the case due to missing incentives to provide detailed information outside the most problematic areas $(C P=2(\sigma=1.75))$. In respect to the hotspots the situation is different, most probably because in Puno Bay various NGO's and international agencies are active (e.g., the Japanese Development Agency) (Méndez Quincho, 2001). Thus, the ALT's performance is estimated to be in the order of $50 \%(\sigma=15 \%)$.

Contamination levels. Revollar (2004a) and Méndez Quincho (2001) report that contamination levels have remained approximately the same in the past 10 years. In 
the inner Puno Bay, which is the only place for which detailed information is available, contamination has increased. Copacabana Bay is continuously affected by high concentrations of persistent heavy metals from mining, although this industry no longer exists. We could not obtain information on the Coata River at Juliaca. More generally, existing studies show that contamination levels are relatively high $(A P=1(\sigma=0.38))$. This situation would be only slightly different without the ALT $(C P=1$ $(\sigma=1.25)$, which means that the ALT has almost certainly had no substantial, positive impact in this respect so $\operatorname{far}(P E R=0(\sigma=0.15))$.

Sewage treatment facilities. According to Revollar (2004b), the master plan does not propose any specific local measures to reduce water pollution. However, some sewage facilities have been constructed to decrease pollution levels (Revollo et al., 2003): a sanitary sewage system in Desaguadero and treatment plants in Copacabana and Desaguadero. Yet, apparently not much has happened in Puno and Juliaca, the most populated cities in the basin. Revollar (2004a) states that many separated, individual efforts have been undertaken in Puno without strong ALT involvement and without significant success. One recent example is an eco-touristic wharf built in Inner Puno Bay. By the installation of an aeration system a natural sewage treatment lagoon was created (Benson, 2004). The municipality also planned to build a treatment plant in 2005 in cooperation with the German development agency (Filies, 2004). Up to date, the built lagoons can treat the wastewater of 40,000 people, out of a total of 120,000 (Benson, 2004). We conclude that some work on sewage facilities has occurred, but that the extent of treated wastewater is still considered insufficient according to regional standards $(A P=3(\sigma=0.13))$. The situation without the ALT would probably not have been very different, since even in the case of Copacabana's sewage treatment systems the ALT only contributed in the form of assisting consultants (Revollar, 2004b). It lacks the financial resources to fund wastewater treatment facilities, which are obviously rather expensive $(C P=2(\sigma=1))$. So far, the ALT has therefore not been effective in supporting the construction of sewage facilities at the hot spots of the basin $(P E R=13 \%(\sigma=11 \%))$.

\section{Summary of the assessment}

The assessment presented above shows that the performance of the ALT is significantly greater than zero for the majority of management objectives (Table 3). However, success with respect to the goals set by the master plan has been rather modest to small. Eight years into the implementation of the master plan only 4 out of 10 attributes were associated with PER scores of $50 \%$ or more.

The uncertainty analysis provides useful information for the interpretation of assessment results. It identifies
PER scores for specific management attributes that, due to the nature of the available information, are particularly uncertain (e.g., diversion of inflows), and it points to the sources of uncertainties in PER scores. In general we observe that the assessment of performance of the ALT is more sensitive to $A P$ than to $C P$. At first sight, this is a promising result. Actual performance is easier to quantify than counterfactual performance, for which at best a qualified guess is possible. However, the contribution of $A P$ to uncertainty of $P E R$ is generally lower than the contribution of $C P$. This indicates that the available information is reasonably good (i.e., our judgment about the credibility of information sources): more accurate data on $A P$ would not seem to reduce the uncertainty of $P E R$ significantly.

\section{Discussion}

In carrying out the performance assessment we found that PER scores are clearly sensitive to several selection effects: (i) choice of attributes, (ii) identification of optimum performance, (iii) time-scale, and (iv) subjectivity of information.

Choice of attributes. The overall assessment of a given international water management effort depends critically on the selection of attributes for which PER scores are computed, i.e. which attributes are included or left out. Decisions by the analyst in this respect depend on available time, financial resources, and access to information. One common selection effect problem is that water management authorities may be more inclined to provide detailed data for attributes where management efforts perform well. If the analyst focuses on such attributes alone, the overall assessment may be too "rosy". We tried to avoid this pitfall by also focusing on management attributes for which only "soft" information was available. However, some parts of the ALT's management efforts could not be included in the assessment because of an almost total lack of reliable information. For example, we learned that a large biodiversity project costing several million dollars is currently being carried out in the TDPS system (ALT, 2004). However, these activities could not be evaluated because the information needed for a reasonably careful assessment could not be acquired. For the same reason, we were forced to limit our assessment to Lake Titicaca, thus excluding major parts of the TDPS located downstream on Bolivian territory. Even though it seems that most of the ALT's activities focus on the great lake, the overall results of our assessment could look different if other parts of the watershed were included. For example, an analysis of the following issues could affect our results: (i) benefits of the Desaguadero regulation works for downstream irrigation agri- 
culture; (ii) impacts of water management on salination in the downstream part of the basin; (iii) environmental and socio-economic impacts of massive pollution from an oil spill of a corporate pipeline on the Desaguadero River, Lake Poopó, and Uru Uru (TED, 2000).

Optimum performance. The results of any performance assessment obviously depend on the definition of the optimum. Definitions of the optimum are problematic if the desired outcome is strategically biased and hence there is a problem of "endogeneity" - e.g. if the PER metric is used by an institution for self-evaluation, and if $O P$ is set artificially low to make performance look better. In the Lake Titicaca case, we argue (see below) that our assessment may be affected by the opposite problem. Experts from European countries, which tend to have very high environmental standards in international comparison, have introduced very ambitious goals into the ALT's master plan. Since our assessment uses those goals as yardsticks our PER scores may - with a view to the technical and financial means available to the two riparian countries - suffer from a downward bias.

Time-scale. International water management problems tend to get solved over several decades rather than years. In our case, the analysis was limited to eight years since the implementation of the master plan began. This may create several problems. First, we need to be aware that the performance measures computed in this article are no more than an interim assessment, because the master plan has a 20 years time-frame. Eight years may not be enough to build engineering works. Capacity building and creation of environmental awareness usually take much longer in any event. Second, performance may vary from year to year. In assessing $A P$ we tended to focus primarily on the most recent year for which reliable data was available. In doing so we assume that $A P$ is generally increasing over time, and that we have not, by chance, caught a year, where $A P$ was unusually low or high. In the Titicaca case this assumption is, arguably, justified because measures are incremental and progress is cumulative. This assumption may not hold in other empirical cases. In any event, a comprehensive assessment of performance needs to pay attention to the timedynamics of $A P$ and $C P$ (and potentially also $O P$ ), to the extent the necessary data is available (such data is largely absent in the Titicaca case). Third, collaboration between countries often has a long history. Hence it is difficult to tell for some management attributes whether progress was made because of the ALT's efforts, or whether the ALT's performance was only an add-on to the effects of previous international collaboration. This problem may lead to a downward bias of $C P$ (and thus upward bias of $P E R$ ). One example is the non-diversion of inflowing rivers into Lake Titicaca.
Subjectivity of information. The performance assessment procedure used in this article involves several subjective elements. Notably, assessment results depend not only on what attributes are chosen, but also on what information for each attribute is included, and whether expert opinions are accurate. We submit that as long as the sources of information as well as the procedures for handling differing information and uncertainties with regard to any given parameter are made explicit this is not a problem. In this article we assessed how the reliability of different sources of information (e.g., scientific papers, books, newspapers, internet sources, personal communications (see references)) might affect performance scores. This uncertainty analysis does not change the results of the assessment, but it delivers complementary information. We agree with Morgan and Henrion (1990) who point out that in policy analysis "uncertainties are not caused, but highlighted through use of the quantification process". In further applications of the performance metric used in this article, we propose to perform an additional robustness check to account for second order uncertainties. The analyst should carefully evaluate the sensitivity towards variations in the assigned degrees of uncertainty as in Table 2 .

With a view to the aforementioned limitations, we submit that the objective of transparency is better served if we present disaggregated results for each management objective. Disaggregation also takes into account that many international water management cases involve multi-dimensional problems and, therefore, management systems with multiple objectives. In fact, being able to establish why performance varies across management objectives constitutes the starting point for explaining why some efforts work better than others.

Finally, we submit that the methodology described and tested in this paper is not only of scientific, but also of practical use. Most large environmental management programs have, in recent years, been accompanied by some sort of evaluation mechanism. In most cases, such evaluation mechanisms have remained at hoc, unsystematic, and rather superficial. In its technically simple form (for a more complex version see Siegfried and Bernauer, 2006), the methodology used in this article could be used also by governmental authorities and NGOs. We see at least two advantages of doing so. First, the methodology permits well-structured, transparent, and standardized assessments that also point to information gaps and uncertainties that need to be addressed. Second, differing or new information can easily and incrementally be incorporated in the analysis by including more attributes and/or updating parameter values.

\section{Conclusion}

In this article, we have tested the usefulness of a new concept for assessing policy performance in international 
water management. Empirically, we have focused on international efforts by Peru and Bolivia at Lake Titicaca. This case is a particularly hard case for applying our performance measurement concept because of limited information, vague or ambiguous management objectives, and a multi-dimensional environmental problem. The objective was not to generate new information on Lake Titicaca, but to establish to what extent a systematic assessment of performance is possible based on existing information.

The assessment, which was carried out with reference to the master plan that was established by the Binational Autonomous Authority of Lake Titicaca (ALT) in 1996, shows that eight years after the implementation of the plan began the performance record is rather modest to poor for the management objectives examined. These objectives pertain to flood and drought protection, water use management, and water quality management. We emphasize that our results are interim results. To what extent the ALT's 1996 objectives will be met at the end of the 20 years period covered by the master plan remains open. In addition, the calculation of the PER scores involves subjective elements and may also be affected by incomplete or incorrect information. We have tried to make our choices (and the problems involved) explicit, so that other scientists can improve our assessment in further research.

More generally, the main challenges in applying the PER metric involve several selection effects: choice of attributes, identification of $O P$, time-scale, and subjectivity of information. We found, however, that the performance assessment concept applied in this article has significant advantages over previous methods: (i) it takes into account counterfactual performance and thus makes a causal connection between policies and their effects; (ii) the analysis can be carried out in a structured, standardized, and transparent manner; (iii) it allows for a quantitative assessment of uncertainties.

In conclusion, we point to some reasons for why the performance of Lake Titicaca management efforts has, thus far, been lower than one might have hoped for. In our view, the key obstacles to effective management of Lake Titicaca are not the usual upstream-downstream conflicts of interest between two or more riparian countries, which we observe in many international water management cases (see Bernauer, 2002). Rather, the key obstacles pertain to socio-economic and political conditions within each of the two riparian countries. In addition, the generally rather low PER scores are in part also produced by the ambitious management objectives set by the master plan.

As shown in Table 1, socio-economic conditions in the TDPS basin are by no means conducive to effective water management. Widespread poverty stands in the way of efforts to increase environmental awareness and to introduce sewage treatment facilities and more efficient irrigation systems. With regard to the ALT itself, funding is reportedly a major problem (La Prensa, 2003; Revollo, 2001), with obvious consequences for the implementation of the master plan. Stakeholder involvement is largely absent. This is justified by the ALT with the somewhat dubious argument that "at present, due to the social and economic instability in both countries, there is no appropriate political climate in which to reach community consensus" (ALT, 2003). Yet, this argument points to a more fundamental problem, namely, weak and unstable political institutions in Bolivia and Peru.

As noted in the discussion, our assessment may suffer from a downward bias. The reason is that the goals of the master plan were defined largely by European experts, that is, experts from countries with comparatively high environmental standards. In other words, low performance, as expressed by the PER scores, may not only stem from unfavorable socio-economic and political conditions, but may partly be the result also of the high standards against which performance is rated.

Some observers have in fact argued that in the TDPS system a first world management plan was imposed on a third world reality. They note that the master plan's recommendations may be clear and technically correct, but the time schedule may be unrealistic for Bolivia and Peru. They also argue that the existence of a binational authority (ALT) and the master plan as such should be considered a success (e.g. Borre et al. 2001). Indeed, the Organization of American States (OAS), the UN Environment Program (UNEP, or PNUMA) as well as other international agencies and NGOs have gained interest in the Lake Titicaca master plan. As a consequence, additional projects could be carried out with their assistance and PER scores could improve considerably over time. Whether one should use the best environmental standards worldwide as benchmarks $(O P)$ for the calculation of $P E R$ or whether $O P$ should be defined at levels that can, with the best of local efforts, be reached, remains open.

\section{Acknowledgments}

The authors are grateful to Alberto Crespo, Marco Revollar, Anne Coudrain, Tom Northcote, Yann L'Hôte, Iris Domínguez Talavera and Leonor Mendez Quincho for sharing their knowledge on Lake Titicaca with us. We are obliged to Tobias Siegfried and Detlef Sprinz for very helpful comments in respect to performance assessment methodology, and to Bernhard Wehrli and Johnny Wüest for comments on an earlier version of this article. We also thank three anonymous reviewers for very valuable comments. 


\section{References}

ALT, 2003. Lake Titicaca Basin. In The UN World Water Development Report - Water for People, Water for Life (UNESCO, ed.), pp. 466-480. http://www.unesco.org/water/wwap/case_studies/ titicaca_lake/titicaca_lake.pdf

ALT, 2004. Internet page of ALT: http://www.pnud.bo/biodiversidadtdps/alt/

Benson, D., 2004. Puno: Pollution in Lake Titicaca. Noticiero Aymara July 25, 2004.

Bernauer, T., 2002. Explaining Success and Failure in International River Management. Aquatic Sciences 64/1: 1-19.

Borre, L., D. R. Barker and L. E. Duker, 2001. Institutional Arrangements for Managing the Great Lakes of the World: Results of a Workshop on Implementing the Watershed Approach. Lakes \& Reservoirs: Research and Management 6: 199-209.

Bourges, J., J. Cortes and E. Salas, 1992. Hydrological Potential. In C. Dejoux and A. Iltis (eds.) Lake Titicaca: A Synthesis of Limnological Knowledge. Kluwer Academic Publishers, Dordrecht, 523-538.

Costantini, M. L., L. Sabetta, G. Mancinelli and L. Rossi, 2004. Spatial Variability of the Decomposition Rate of Schoenoplectus Tatora in a Polluted Area of Lake Titicaca. Journal of Tropical Ecology 20: 325-335.

Crespo, A., 2004. Personal communication with the authors. La Paz, Bolivia.

Dejoux, C. and A. Iltis, 1992. Lake Titicaca: A Synthesis of Limnological Knowledge. Kluwer Academic Publishers, Dordrecht, $584 \mathrm{pp}$.

Durth, R., 1996. Grenzüberschreitende Umweltprobleme und regionale Integration. Zur politischen Ökonomie von OberlaufUnterlauf-ProblemenaninternationalenFlüssen.(Transboundary Environmental Problems and regional Integration. On the political Economy of upstream-downstream problems at international rivers.) Nomos, Baden-Baden.

Filies, F., 2004. Personal communication with the authors. GTZ (German agency for technical cooperation), Lima, Peru.

La Prensa, 2003. La playa de Copacabana no es apta para los bañistas (The beach of Copacabana is not suited for swimmers). La Prensa, Agosto 17, 2003, http://www.laprensa.com. bo/20030817/ciudad/ciudad02.htm

Liu, J. S., 2001. Monte Carlo Strategies in Scientific Computing. New York: Springer.

Marty, F., 2001. Managing International Rivers: Problems, Politics and Institutions. Bern, Peter Lang.

Méndez Quincho, L., 2001. Estudio de la calidad del agua de la bahía interior de Puno (Water quality study of inner Puo bay). Revista del Instituto de Investigación, Universidad Nacional Agraria La Molina, Peru, 4(8), http://sisbib.unmsm.edu.pe/bibvirtual/publicaciones/geologia/Vol4_N8_2001/consultas_publicas $\% 20 . h t m$
Morgan, M. G. and M. Henrion, 1990. Uncertainty: A Guide to Dealing with Uncertainty in Quantitative Risk and Policy Analysis, Cambridge University Press, Cambridge, 344 pp.

NASA, 2004. Satellite images, http://www.geographynetwork.com

Northcote, T. G., 1992. Contamination. In C. Dejoux and A. Iltis (eds.) Lake Titicaca: A Synthesis of Limnological Knowledge. Kluwer Academic Publishers, Dordrecht, pp. 551-561.

Northcote, T. G., P. Morales, D. A. Levy and M. S. Greaven, 1989. Pollution in Lake Titicaca, Peru: Training, Research and Management. Westwater Research Centre, University of British Columbia, Vancouver, Canada.

Paredes, M. A. and R. Gonfiantini, 1999. Lake Titicaca: History and Current Studies. Water \& Environment News, International Atomic Energy Agency, Vienna, Austria, 8/9, 6-8.

Querol, M., 2003. Estudio sobre los convenios y acuerdos de cooperacion entre los paises de America Latina y el Caribe, en relacion con sistemas hidricos y cuerpos de agua transfronterizos (Study on the conventions and cooperation agreements between the Latin American and Caribbean states in relation to hydrological systems and international water bodies). United Nations, Santiago de Chile.

Revollar, M., 2004a. Internal Report. PELT, Puno, Peru.

Revollar, M., 2004b. Personal communication with the authors. PELT, Puno, Peru.

Revollo, M., 2001. Management Issues in the Lake Titicaca and Lake Poopo System: Importance of Developing a Water Budget. Lakes \& Reservoirs: Research and Management 6: 225-229.

Revollo, M., M. Liberman and A. Lescano, 2003. Lake Titicaca. In: Lake Basin Management Initiative - Regional Workshop for Europe, Central Asia and the Americas, Vermont, USA.

Saltelli, A., 2000. Sensitivity Analysis, John Wiley \& Sons, Chichester.

Saltelli, A., 2004. Sensitivity Analysis in Practice: A Guide to Assessing Scientific Models, John Wiley \& Sons, Chichester.

Siegfried, T. and T. Bernauer, 2006. Measuring International Policy Performance. Manuscript.

TED, 2000. The Desaguadero Oil Spill, Trade Environment Database (TED) http://www.american.edu/TED/bolpipes.htm

Underdal, A., 1992. The Concept of Regime 'Effectiveness'. Cooperation and Conflict 27/3: 227-240.

UNESCO, 2004a. World Water Assessment Program - Lake Titicaca Basin. http://www.unesco.org/water/wwap/case_studies/ titicaca_lake/old_index.shtml

UNESCO, 2004b. World Water Assessment Program - Lake Titicaca Basin. http://www.unesco.org/water/wwap/case_studies/ titicaca_lake/detailed_view.shtml

Wolf, A., 1997. International Water Conflict Resolution: Lessons from Comparative Analysis. International Journal of Water Resources Development 13/3: 333-365. 